\title{
LA VECINDAD CON ESTADOS UNIDOS: INTERÉS NACIONAL Y OPINIÓN PÚBLICA
}

\author{
LAURA DE OLden*
}

EN EL ESTUDIO DE LA OPINIÓN PÚBLICA MEXICANA, la investigación sobre el proceso de formación de preferencias individuales exclusivas al ámbito de la política internacional de México es limitada. El objetivo de este ensayo es estudiar el proceso de formación de preferencias individuales en materia de política exterior usando como marco teórico la perspectiva de opinión pública individual racional propuesta por Page y Bouton. ${ }^{1}$ La tesis de sistemas racionales de opinión pública individual se basa en la existencia de predisposiciones relativamente estables que orientan las respuestas en los sondeos de opinión y que permiten a los ciudadanos, independientemente de sus características demográficas y limitaciones cognitivas, hacer juicios razonables -autónomos, coherentes y diferenciados- sobre los distintos componentes de la política exterior. ${ }^{2}$

Mucho se ha escrito sobre la influencia de la proximidad geográfica con los Estados Unidos y su efecto en la memoria histórica nacional, la identidad nacional y su incidencia en la vida política y económica del país. Lo que se ha estudiado poco es

* El trabajo aquí presentado forma parte de la investigación de Laura De Olden, "Purposive Belief Systems in U.S.-Mexican Relations: A Mexican Test of Page and Bouton's Theory of Purposive Belief Systems" (2013). La autora agradece los comentarios de Benjamín I. Page, Dan Galvin y Jason Seawright de Northwestern University, de Gerardo Maldonado y Rodrigo Morales Castillo del cide y del equipo de México, Las Américas y el Mundo.

${ }^{1}$ B. I. Page y M. M. Bouton, The Foreign Policy Disconnect : What Americans Want from our Leaders but Don't Get, Chicago, University of Chicago Press, 2006.

${ }^{2}$ El término utilizado por Page y Bouton, op. cit., es "purposive belief systems"; en esta investigación se utilizará el término sistema de creencias y valores instrumentales. 
cómo las actitudes hacia ese país se asocian en las mentes de los mexicanos con las percepciones de interés nacional y seguridad nacional, y cómo éstas a su vez afectan la formación de preferencias individuales en materia de política exterior. ${ }^{3}$ Dado que la vecindad con Estados Unidos opera como la condicionante más importante de la política exterior y como limitación a la soberanía de México, ${ }^{4}$ este trabajo tiene el objetivo de analizar las percepciones individuales asociadas con la vecindad y sus implicaciones en la formación de preferencias sobre el papel que debe desempeñar México en el ámbito internacional.

Para explorar la manera en la cual los mexicanos forman sus preferencias sobre los costos y los beneficios para México asociados con la vecindad con Estados Unidos, se desarrolla un modelo multivariado que utiliza datos sobre opinión pública individual obtenidos de la encuesta México, las Américas y el Mundo 2010 del Centro de Investigación y Docencia Económicas (CIDE). El análisis empírico aquí realizado demuestra que el ciudadano común, el de a pie, 1) tiene preferencias coherentes y diferenciadas, con contenido

${ }^{3}$ Gran parte de los trabajos empíricos basados en modelos estadísticos multivariados que analizan las preferencias ciudadanas sobre temas de política exterior de México se han concentrado en la reforma económica (Kaufman y Zuckermann, "Attitudes toward Economic Reform in Mexico: The Role of Political Orientations”, The American Political Science Review, vol. 92, núm. 2, 1998, pp. 359-375; S. C. Stokes et al., "Opinión pública y reformas de mercado: Las limitaciones de la interpretación económica del voto”, Desarrollo Económico, vol. 37, núm. 145, 1997, pp. 31-56), la inversión y el comercio internacional (C. L. Davis, "Mass Support for Regional Economic Integration: The Case of NAFTA and the Mexican Public", Mexican Studies/Estudios Mexicanos, vol. 14, núm. 1, 1998, pp. 105-130; y C. L. Davis y H. A. Bartilow, "Cognitive Images and Support for International Economic Agreements with the United States Among Mexican Citizens", Latin American Politics and Society, vol. 49, núm. 2, 2007, pp. 123-148. También: A. Moreno, "Mexican Public Opinion toward NAFTA and FTAA", en E. J. Chambers y P. H. Smith, NAFTA in the New Millennium, La Jolla y Edmonton, University of California San Diego and University of Alberta Press, 2002; M. A. Kocher y S. Minushkin, "Trade and Investment Policy Preferences and Public Opinion in Mexico", Annual Meeting of the International Studies Association, San Diego, CIDE, 2006).

${ }^{4} \mathrm{~J}$. Z. Vázquez y L. Meyer, México frente a Estados Unidos. Un ensayo histórico, 1776-2000, México, FCE, 2001; y M. Ojeda, Alcances y límites de la política exterior de México, México, El Colegio de México, 2006. 
político real, 2) cuenta con conocimientos suficientes y actitudes formadas para ponderar las ventajas y desventajas para México asociadas con la vecindad con Estados Unidos, y 3) tiene la capacidad de elegir la dirección que México debe seguir en el ámbito internacional.

En términos normativos, la incidencia de la opinión ciudadana sobre la definición de políticas públicas, incluida la definición de política exterior, debe ser fundamental en cualquier régimen democrático. Como lo apunta Dahl, una característica fundamental de la democracia es la "continua capacidad de respuesta de los gobiernos a las preferencias de los ciudadanos, considerados como políticamente iguales". ${ }^{5}$ Las encuestas representativas de la población nacional nos permiten saber con precisión las preferencias ciudadanas en torno a las políticas de gobierno, a la vez que garantizan igualdad de oportunidad para expresar dichas preferencias. En este sentido, el uso de encuestas representativas de opinión contribuye a reforzar y profundizar los procesos democráticos al proveer de insumos para tomar decisiones políticas que incorporen una base social.

A pesar de su carácter democrático, el uso de encuestas en el ámbito del diseño de políticas públicas -y en particular de política exterior- es objeto de debate. Gran parte del debate académico se ha enfocado en cuestionar la capacidad del ciudadano común para obtener y retener información y usarla para formular opiniones coherentes y estructuradas en materia de política pública, y en específico en la política exterior. El argumento de que el ciudadano común no tiene conocimientos suficientes ni preferencias sólidas sobre temas de interés público ataca la base de la teoría de la democracia representativa, que supone no sólo una opinión autónoma de los ciudadanos, sino que exige que sus preferencias influyan en las políticas de gobierno. ${ }^{6}$

Este trabajo se divide de la siguiente manera: primero, se hace un breve recuento de los trabajos seminales sobre el estudio de la opinión pública que son relevantes para esta investigación;

${ }^{5}$ R. A. Dahl, Polyarchy: Participation and Opposition, New Haven / Londres, Yale University Press, 1971.

${ }^{6}$ H. F. Pitkin, The Concept of Representation, Berkeley, University of California Press, 1967; y R. A. Dahl, Polyarchy: participation and opposition, New Haven / Londres, Yale University Press, 1971. 
segundo, se presenta un marco conceptual para el caso mexicano; y tercero, se desarrolla un modelo estadístico multivariado sobre los factores predictivos de las evaluaciones costo-beneficio de la vecindad con Estados Unidos.

\section{OPINIÓN PÚBLICA Y POLÍTICA EXTERIOR: ENFOQUES TEÓRICOS}

En la ciencia política existe un debate académico importante sobre el lugar que debe ocupar la opinión pública ${ }^{7}$ en la formulación de políticas públicas. Los trabajos clásicos de Walter Lippmann y Gabriel Almond cuestionan la capacidad del ciudadano común, para definir preferencias políticas en materia de política exterior. ${ }^{8}$ Holsti apunta que durante la Guerra Fría se articuló un acuerdo académico conocido como el consenso "Almond-Lippmann", cuyos supuestos básicos disponían que: 1) el ciudadano común carece del tiempo, interés, capacidad cognitiva e información necesaria para comprender y analizar políticas públicas; 2) las preferencias ciudadanas en materia de política exterior carecen de estructura y coherencia ideológica; y 3) la opinión pública es volátil -varia de forma aleatoria-y por tanto no debe ser considerada como un fundamento en la elaboración de políticas públicas, particularmente cuando se trata de política exterior. ${ }^{9}$ Estos supuestos fueron sustentados por los primeros estudios empíricos en la materia, entre ellos destacan Campbell y colaboradores y Converse. Mediante un diseño longitudinal de panel, Converse concluye que el público carece de preferencias sólidas y actitudes verdaderas: las opiniones individuales no se integran en conjuntos coherentes de orientación

${ }^{7}$ Opinión pública denota el conjunto de percepciones y preferencias que portan los individuos y que se capturan por medio de la técnica de encuesta.

${ }^{8}$ W. Lippmann, Public Opinion, Nueva York, Harcourt, 1922; W. Lippmann, The Phantom Public, Nueva York, Harcourt Brace, 1925; G. A. Almond, The American People and Foreign Policy, Nueva York, Harcourt Brace, 1950; y G. A. Almond, "Public Opinion and National Security Policy", The Public Opinion Quarterly, 1956, vol. 2, pp. 371-378.

${ }^{9}$ O. R. Holsti, "Public Opinion and Foreign Policy: Challenges to the Almond-Lippmann Consensus Mershon Series: Research Programs and Debates”, International Studies Quarterly, 1992, vol. 36, núm. 4, pp. 439-466. 
político-ideológicas, son aleatorias e inestables. Bajo este esquema, el ciudadano común carece de preferencias estructuradas, coherentes, consistentes, en suma racionales. ${ }^{10}$

Mientras que hay evidencia empírica que apunta a la existencia de un público generalmente desinformado, ${ }^{11}$ el debate académico actual se divide entre quienes argumentan que los individuos tienen la capacidad de formular preferencias estructuradas, coherentes y consistentes sobre políticas públicas y quienes sostienen que no. Las perspectivas teóricas varían así como el nivel de análisis de datos duros -individual o agregado-.

Una de las corrientes de análisis de opinión pública que toma en cuenta las limitaciones cognitivas de los ciudadanos es el estudio de la opinión pública agregada, analizada a lo largo del tiempo. Entre los trabajos estadounidenses más destacados -tanto por la magnitud del trabajo empírico como por el aporte que hacen al debate académico- está The Rational Public de Benjamin I. Page y Robert Shapiro. El análisis empírico de las preferencias sociales de los norteamericanos en temas de política interna y exterior de 1935 a 1990 identifica la existencia de patrones de comportamiento propios de la opinión pública agregada: es estable, consistente e inmune a los errores de medición, a los límites impuestos por la información imperfecta y a la volatilidad e inconsistencia registradas en las percepciones y preferencias individuales. El fundamento del argumento de Page y Shapiro es estadístico y se basa en la ley de los grandes números: en cada punto del tiempo las respuestas individuales pueden diferir de las preferencias de largo plazo; pero si las diferencias son aleatorias y se pregunta a un número elevado de individuos, las mutaciones se neutralizan afianzando una tendencia central de opinión a largo plazo. ${ }^{12} \mathrm{Al}$ analizar el comportamiento agregado de las preferencias ciudadanas, Page y Shapiro

${ }^{10}$ A. Campbell et al., The American Voter, Nueva York, Wiley, 1960; y P. E. Converse, "The Nature of Belief Systems in Mass Publics", en D. E. Apter, Ideology and Discontent, [Nueva York,] Free Press, 1964, pp. 206-264.

${ }^{11}$ M. X. Delli Carpini y S. Keeter, What Americans Know about Politics and Why it Matters, New Haven, Yale University Press, 1996.

12 B. I. Page y R. Y. Shapiro, The Rational Public: Fifty Years of Trends in Americans' Policy Preferences, Chicago, University of Chicago Press, 1992. 
demuestran que la opinión pública colectiva se comporta de manera estable y consistente a lo largo del tiempo, y que cuando hay un cambio estadísticamente significativo en las preferencias colectivas, éste, lejos de ser errático, caprichoso o volátil, corresponde al impacto específico en las preferencias sociales proveniente de un cambio en el contexto internacional, social o económico. Es decir, cuando la opinión colectiva cambia, lo hace de un modo comprensible y predecible. ${ }^{13} \mathrm{Al}$ revelar la existencia de mayorías razonables, ${ }^{14}$ Page y Shapiro sostienen que el público, como colectivo, tiene la capacidad soberana de gobernar y que las encuestas de opinión pública, al recoger preferencias reales, diferenciadas, coherentes y consistentes deben ser una guía veraz para los partidarios de sistemas de gobierno democráticos. ${ }^{15}$

En The Foreign Policy Disconnect, Page y Bouton fortalecen el argumento del público racional enfocando su análisis en el comportamiento de las preferencias individuales del ciudadano: cómo y por qué los individuos estructuran sus preferencias sobre política exterior. La investigación de Page y Bouton se enfoca en las preferencias ciudadanas sobre política exterior e internacional, un rubro donde los críticos de la opinión pública han argumentado que los ciudadanos están especialmente incapacitados para expresar preferencias informadas, diferenciadas, coherentes y autónomas. Page y Bouton presentan una investigación empírica que demuestra que los ciudadanos poseen preferencias con contenido político real y las sustentan en un sistema de valores fundamentales que contribuyen a la existencia de sistemas racionales de opinión pública individual que -una vez agregadas- contribuyen a la racionalidad colectiva.

Si bien su modelo teórico no niega la existencia de desventajas informativas del público en general, la tesis principal de Page y Bouton es que los ciudadanos hacen uso de sistemas de creencias y valores basados en objetivos fundamentales de política exterior que les permiten hacer juicios razonables sobre sus distintos

${ }^{13}$ Ibid., p. 385.

${ }^{14}$ Page y Shapiro aluden al Teorema de Condorcet: las leyes estadísticas aseguran que una mayoría -y no una minoría- tiene mayor probabilidad de tomar una decisión correcta o razonable. Ibid., p. 26

15 Ibid., p. 383. 
componentes. La tesis principal es que los ciudadanos organizan sus preferencias de manera instrumental: la elección entre alternativas concretas de política exterior está delimitada por la asociación directa que existe entre éstas y las preferencias sobre los objetivos de política exterior, las percepciones de cómo mejor alcanzar dichos objetivos (como el multilateralismo, mecanismos de cooperación bilateral o liderazgo regional) y las percepciones de problemas y amenazas internacionales. Estas, a su vez, están asociadas de manera directa con un sistema de actitudes ideológicas (como las actitudes frente a los principios de internacionalismo, aislacionismo, liberalismo económico, orientación ideológica), predisposiciones políticas (incluidas entre otras la orientación izquierda-derecha e identidades partidarias) que se sustentan en creencias y valores propios y predominantes en la sociedad (como valores relacionados con la identidad nacional y la soberanía nacional y las percepciones de vulnerabilidad interna o internacional). Finalmente, los sistemas de creencias y valores están arraigados, a su vez, en la experiencia internacional histórica, la exposición a la información internacional y a las características socio-demográficas de los individuos. ${ }^{16}$ En resumen, las opiniones fundadas y racionales 1) se asientan en los valores fundamentales predominantes de la sociedad y 2) manifiestan patrones de coherencia conceptual basados en la relación a esos valores. ${ }^{17}$

Page y Bouton profundizan el argumento de ciudadano racional demostrando empíricamente que, en la mayoría de los casos, la capacidad del ciudadano para formular opiniones autónomas, coherentes y diferenciadas sobre políticas públicas, en específico sobre política exterior, no depende directamente de las características socio-económicas o demográficas de los individuos. Su análisis estadístico demuestra que, en el caso del público estadounidense, no existen diferencias significativas entre individuos de mayor y menor estatus socio-económico en su habilidad para juzgar lo intereses de política exterior y ligarlos a políticas públicas específicas consistentes con alcanzar dichos objetivos. Esta conclusión es de relevancia

${ }^{16}$ B. I. Page y M. M. Bouton, The Foreign Policy Disconnect: What Americans Want from Our Leaders But Don't Get, Chicago, University of Chicago Press, 2006, p. 29-30. 17 Ibid. 
mayor, ya que ataca la base de los argumentos presentados por los críticos de la opinión de la gente común sobre la carente capacidad del ciudadano de a pie para poseer actitudes verdaderas en materia de política exterior.

\section{LA VECINDAD CON ESTADOS UNIDOS DEFINE LAS PRIORIDADES DE INTERÉS Y SEGURIDAD NACIONAL EN LA OPINIÓN PÚBLICA MEXICANA}

Vázquez y Meyer señalan que "la existencia misma de México como país independiente ha estado subordinada al resultado del choque entre la violenta expansión territorial y económica de Estados Unidos y la capacidad de la sociedad y los gobiernos de México para resistir este embate". ${ }^{18}$ En la actualidad, la realidad geopolítica de México definida por su vecindad con Estados Unidos, la enorme dependencia económica frente a ese país y la difícil agenda de problemas transnacionales compartidos, hacen de la vecindad con Estados Unidos un tema de interés y seguridad nacional para México.

¿Cuál es la valoración que hacen los mexicanos sobre la vecindad con Estados Unidos y cómo se relaciona ésta con los objetivos de política exterior percibidos como prioritarios por los mexicanos? Comparar los resultados de 2004 a 2012 de la encuesta México, las Américas y el Mundo permite obtener varias lecturas importantes sobre los objetivos de la política exterior mexicana en la opinión pública y sobre cómo estos objetivos se relacionan con la posición geopolítica de México y con las percepciones ciudadanas sobre los costos / beneficios para el país asociados con la vecindad con los Estados Unidos. En primer lugar, nos permite obtener información sobre el orden de los objetivos de política exterior en la opinión pública mexicana y ver que en la mayoría de los casos se observa consistencia y continuidad en la importancia otorgada a dichos objetivos a lo largo del tiempo. Segundo, los mexicanos consideran que los objetivos o prioridades de política

18 J. Z. Vázquez y L. Meyer, México frente a Estados Unidos. Un ensayo histórico, 1776-2000, México, FCE, 2001, p. 9. 
exterior son aquellos que inciden positivamente en su bienestar económico o de seguridad. ${ }^{19}$ Tercero, e importante para los propósitos de esta investigación, nos permite apreciar con claridad que las valoraciones de los mexicanos sobre cuáles son los objetivos de política exterior más importantes para México coinciden con las valoraciones que los mexicanos hacen sobre los aspectos más importantes de la relación bilateral México-Estados Unidos.

Una importantísima mayoría, $74 \%$ del público y $97 \%$ de los líderes mexicanos, considera que la relación con Estados Unidos es "algo" o "muy importante". ${ }^{20}$ Cuando se pregunta a los mexicanos cuál es el aspecto más importante de la relación México-Estados Unidos, la mayoría de los mexicanos estima en primer lugar, comercio e inversión; en segundo, el narcotráfico y crimen organizados; en tercero, seguridad fronteriza; y en cuarto, migración, ${ }^{21}$ temas que son, a su vez considerados los máximos objetivos de la política exterior de México (tabla 1). Es decir, la vecindad con Estados Unidos define las prioridades de interés nacional para los mexicanos. Para la gran mayoría los objetivos máximos de la política exterior son aquellos que 1) inciden directamente en su bienestar económico o seguridad y 2) forman parte de la agenda bilateral con Estados Unidos.

Siguiendo el marco teórico de sistemas de creencias y valores instrumentales, las valoraciones que se tengan sobre la vecindad, entendida ésta como tema de interés y seguridad nacional para los mexicanos, deben estar asociadas con 1) las características sociodemográficas de los mexicanos y su exposición a la información internacional; 2) un sistema de creencias y valores propios y predominantes en la sociedad mexicana, producto de la experiencia internacional histórica de México; 3) percepciones ciudadanas sobre soberanía nacional basadas en consideraciones acerca de la vulnerabilidad interna e internacional de México; y 4) preferencias ciudadanas sobre cuál debe ser la actuación internacional de México, tanto en el ámbito multilateral como en el de cooperación bilateral

19 G. González González et al., "Política exterior: opinión pública y líderes", México, Las Américas y el Mundo, 2010, México, CIDE, 2011.

${ }^{20}$ G. González González et al., "Política exterior: opinión pública y líderes", México, las Américas y el Mundo 2012-2013, México, CIDE, 2013.

${ }^{21}$ Loc. cit. 
con Estados Unidos. Con el fin de explorar esta relación de manera empírica, se desarrolla un modelo multivariado para explicar las opiniones mexicanas sobre la vecindad y entender sus determinantes. Siguiendo este marco analítico, el estudio de la opinión pública en México debe estar indisolublemente relacionado con valores e intereses condicionados histórica y culturalmente. En este sentido, el modelo estadístico desarrollado en esta investigación es justificable en función de las circunstancias históricas y de los intereses y valores específicos de los mexicanos.

Los datos individuales de opinión pública provienen de México, las Américas y el Mundo 2010, una encuesta representativa del ámbito nacional que se llevó a cabo con entrevistas personales a 2400 encuestados mayores de 18 años del 27 de septiembre al 29 de octubre de 2010. La metodología de muestreo fue un diseño estratificado, de múltiples niveles y conglomerados, que posteriormente se ponderó por edad y género. El error muestral es de $\pm 2.04 \%$. La técnica de análisis es regresión lineal, con estimación de mínimos cuadrados ordinarios (oLs) que tiene el objetivo de analizar las asociaciones entre los diferentes elementos del modelo teórico. ${ }^{22}$ Se utilizan las opiniones favorables como la categoría de base para la comparación estadística y el análisis se enfoca en los coeficientes de regresión estandarizados -coeficientes Beta- que son directamente comparables entre sí y que proporcionan información sobre la importancia relativa de cada variable independiente en la ecuación de regresión.

${ }^{22}$ Siguiendo el trabajo seminal de Page y Bouton, op. cit., en esta investigación se ha optado por el uso de regresión lineal (ols) como técnica estadística utilizada para estudiar y cuantificar la relación entre variables. El coeficiente de determinación corregido obtenido en el análisis de regresión lineal para las variables dicótomas subestima el grado de ganancia que podemos obtener al predecir una variable. Las modelizaciones de tipo logit y probit -que con el uso de funciones no lineales permiten acotar el rango de la estimación- arrojaron resultados similares, indicando incluso relaciones aún más fuertes entre variables. En este trabajo se presentan los coeficientes de regresión lineal estandarizados (oLS), principalmente porque poseen una interpretación más intuitiva y permiten valorar la importancia relativa de cada variable independiente dentro de la ecuación. 


\section{Determinantes de las EVAlUaCiOneS COSTO-BENEFICIO SOBRE LA VECINDAD CON ESTADOS UNIDOS}

¿Qué piensan los mexicanos sobre la vecindad con Estados Unidos?, ¿la consideran más una ventaja para México o un problema? Y ¿qué explican las percepciones individuales sobre la vecindad? ¿Cuáles son sus determinantes? Desde 2008, el porcentaje de la población mexicana que considera que la vecindad representa para México más ventaja que problema está en aumento: $45 \%$ en 2008, $52 \%$ en 2010 y $57 \%$ en 2012. Las diferencias regionales también son patentes en este rubro: en el sur, el porcentaje de la población que considera que la vecindad con Estados Unidos es más una ventaja subió de $40 \%$ en 2006 a 48\% en 2012; en el centro, de 50\% en 2006 a $57 \%$ en 2012. El norte del país por lo general ha tenido opiniones más favorables con respecto a la cercanía con Estados Unidos en comparación a otras regiones del país, reportando el porcentaje más alto en 2006 con $72 \%$.

Para analizar la variación de las actitudes mexicanas con respecto a la vecindad, se construye una variable dicótoma que recoge las actitudes desde una perspectiva costo-beneficio: “¿Qué se acerca más a lo que usted piensa: ser vecino de Estados Unidos representa para México más ventaja que problema o más problema que ventaja?". Las opiniones favorables se usan como la categoría de base para la comparación estadística y se desarrolla un modelo multivariado que relaciona su asociación con:

Las características socioeconómicas y demográficas de la población (edad, género, raza, residencia urbana o rural, nivel educativo, nivel de ingreso, región del país).

Exposición a la información sobre México, Estados Unidos y acontecimientos internacionales mediante seguimiento de medios, viajes y participación en redes de comunicación transnacional.

Valores, actitudes ideológicas y predisposiciones políticas. Valores relacionados con la identidad nacional mexicana arraigados en factores endógenos, como las percepciones individuales sobre los extranjeros, y exógenos, como las actitudes y sentimientos hacia Estados Unidos. Actitudes ideológicas, que incluyen aquellas relacionadas con el liberalismo económico, el internacionalismo activo 
y el nacionalismo mexicano. Predisposiciones políticas, donde se incluyen orientación izquierda-derecha e identidades partidarias.

Percepción de soberanía nacional vinculadas a percepciones de vulnerabilidad interna e internacional, que incluyen, entre las primeras, percepciones socio-trópicas sobre el estado general de la económica nacional y evaluaciones retrospectivas sobre logros nacionales en materia de independencia, igualdad social, desarrollo económico y paz y seguridad interna; y dentro de las segundas, evaluaciones retrospectivas y prospectivas sobre la relación bilateral con Estados Unidos.

$$
\text { Ecuación 1. } Y=\beta_{0}+X_{1} \beta_{1}+X_{2} \beta_{2}+X_{3} \beta_{3}+X_{4} \beta_{4}+\varepsilon
$$

$Y=$ la vecindad con Estados Unidos representa una ventaja para México

$X_{1}=$ matriz de observaciones variables demográficas

$\beta_{1}=$ vector de coeficientes variables demográficos

$X_{2}=$ matriz de observaciones información internacional y conexiones EE. UU.

$\beta_{2}=$ vector de coeficientes información internacional y conexiones EE. UU.

$X_{3}=$ matriz de observaciones valores fundamentales, actitudes ideológicas y predisposiciones políticas

$\beta_{3}=$ vector de coeficientes valores fundamentales, actitudes ideológicas y predisposiciones políticas

$X_{4}=$ matriz de observaciones vulnerabilidad relativa frente a EE. UU.

$\beta_{4}=$ vector de coeficientes vulnerabilidad relativa frente a EE. UU.

$\varepsilon=$ componente aleatorio

Para estudiar los determinantes del interés nacional, definido por las percepciones que se tienen sobre las implicaciones costobeneficio de la vecindad con Estados Unidos, se desarrollan cuatro modelos de regresión secuencial. El primer modelo incluye variables socio-económicas y demográficas -edad, género, raza, educación, ingreso, residencia rural vs. urbana, residencia geográfica norte, sur, centro- que podrían tener incidencia en el proceso de socialización y adquisición de creencias y valores relevantes a la 
formación de percepciones sobre el interés nacional de los mexicanos. Se incluyen también en el modelo variables que miden la exposición a la información internacional mediante seguimiento de medios y viajes, ${ }^{23}$ así como mecanismos sociales de conexión con Estados Unidos, como la presencia de familiares que viven en el extranjero y la recepción de remesas. ${ }^{24}$ Con respecto a seguimiento de medios, se utilizaron preguntas sobre interés y seguimiento de noticias sobre las relaciones de México con otros países; finanzas y economía y la situación política y social de México para construir un índice agregado, ampliamente respaldado por los datos. ${ }^{25}$ Las expectativas iniciales para estas variables son las siguientes: la edad debe estar relacionada negativamente con las opiniones favorables, de acuerdo con la idea de que los adultos jóvenes mexicanos de la era post-TLCAN están más expuestos a la forma de vida estadounidense que los de mayor edad. Siguiendo la teoría de la modernización que estipula que los segmentos más modernos de la sociedad por lo general son más receptivos a la apertura de sus países con el exterior, la educación, el ingreso, la residencia urbana, un mayor grado de exposición a la información sobre Estados Unidos -mediante seguimiento de medios y viajes-, deben estar positivamente relacionados con las opiniones favorables sobre las

${ }^{23} \mathrm{Si}$ bien la pregunta sobre viajes no se refiere específicamente a Estados Unidos, es razonable suponer que, dada la vecindad geográfica y dado el número de mexicanos que vive de manera permanente en ese país, esta variable puede fungir como proxy para medir vínculos de interacción con Estados Unidos. Como es costumbre en los estudios de opinión pública, para construir esta variable se agruparon y recodificaron los valores más altos, se agregó uno y se utilizó el Log 10.

${ }^{24}$ La migración mexicana se concentra de manera abrumadora en Estados Unidos, donde radican 11.4 millones de mexicanos. La mayoría de las remesas que recibe México provienen de ese país. Para los propósitos de esta investigación se construyó una variable compuesta de dos preguntas distintas y que captura las opiniones de quienes tienen familiares en el extranjero y reciben dinero del extranjero.

${ }^{25}$ Se generó un alfa de Cronbach de .818. Conviene precisar que a lo largo de esta investigación, las respuestas "no sé" o "no contesto" fueron agrupadas y codificadas como valores faltantes. Los índices agregados han sido codificados de manera creciente/positiva. Como método de imputación durante la construcción de índices agregados y variables compuestas se utilizó la sustitución por la media (se sustituyó el valor ausente por la media de los valores válidos). 
ventajas para México que pueden estar asociadas con la vecindad. Por su parte, estado fronterizo y parientes deben estar directamente asociados con opiniones favorables dados los vínculos sociales y económicos, así como las redes transnacionales de comunicación que tiene este segmento de la población con el vecino del norte.

El segundo modelo incluye un grupo de variables que captura las distintas dimensiones de los valores, creencias fundamentales y predisposiciones políticas e ideológicas de los mexicanos que tienen relevancia en la formulación de opiniones individuales sobre política exterior de México. El estudio empírico de Page y Bouton demuestra que, en el caso estadounidense, los valores fundamentales condicionados histórica y culturalmente y las predisposiciones políticas e ideológicas son las que tienen mayor impacto sobre las preferencias específicas de política exterior, ya que -al ser adquiridas por los individuos a una edad temprana- tienden a ser estables a lo largo del tiempo. En ese sentido, es razonable asumir que dichos valores y predisposiciones políticas actúan como causas y no como efectos de las percepciones y preferencias individuales sobre los objetivos nacionales, y como se analizará más adelante, sobre los mecanismos favorecidos para alcanzar dichos objetivos.

La identidad nacional mexicana se origina, en buena parte, en las precepciones nacionales sobre los Estados Unidos y sobre los estadounidenses. ${ }^{26}$ Enrique Krauze lo resume así: "México nació mirándolos a ellos, a Estados Unidos". ${ }^{27}$ Morris presenta un análisis de literatura académica que usa como referente a Estados Unidos en la construcción del nacionalismo mexicano y destaca su complejidad paradójica: por un lado, la identidad mexicana está definida por aquellos rasgos que la distinguen de la estadounidense, incluso al punto de definirla como anti-americana y, por otro, conlleva un componente de admiración hacia los vecinos del

${ }^{26}$ Véase S. D. Morris (Gringolandia: Mexican Identity and Perceptions of the United States, Lanham, Rowman \& Littlefield, 2005) para un análisis comparativo de los trabajos seminales de Octavio Paz, Carlos Fuentes, Jorge Castañeda, Vasconcelos y Carlos Monsiváis sobre el referente estadounidense en la construcción de la identidad nacional mexicana.

${ }^{27}$ E. Krauze, "Mirándolos a ellos. Actitudes mexicanas frente a Estados Unidos”, Letras Libres, 2007, pp. 32-40. 
norte, que son percibidos como el modelo de desarrollo económico y democrático a seguir en la era moderna. ${ }^{28}$

La desconfianza hacia Estados Unidos ha sido también un rasgo característico del nacionalismo mexicano. Su estímulo a través de los libros de texto de primaria obligatorios ${ }^{29}$ contribuyó al proceso de socialización temprana de estos valores. ${ }^{30}$ La suspicacia y la desconfianza se promovieron como prismas a través de los cuales se debía pensar en Estados Unidos: México podía depender de su vecino pero no confiar en él. ${ }^{31}$ Esto contribuyó también a aumentar la complejidad paradójica de la identidad nacional: por un lado, admiración hacia Estados Unidos como el modelo de desarrollo económico y democrático a seguir, y, por el otro, desconfianza y suspicacia. No fue sino hasta que Carlos Salinas redefine el proyecto de desarrollo nacional frente a Estados Unidos que se pasa, como lo apuntan Vázquez y Meyer, de la búsqueda de una independencia relativa a una integración o "matrimonio de conveniencia", ${ }^{32}$ y se replantea, desde la esfera más alta del poder en México, la narrativa de desconfianza por una de cooperación, respeto y beneficio mutuo. ${ }^{33}$

A veinte años de la firma del acuerdo comercial con Estados Unidos, México no ha podido evitar que el conflicto empañe los esfuerzos de cooperación bilateral en problemas relacionados con la seguridad nacional de ambos países como la lucha contra el narcotráfico y el crimen organizado; ${ }^{34}$ tampoco ha podido convencer

${ }^{28}$ Morris, op. cit.

${ }^{29}$ Véase Morris (op. cit.) para un análisis comparativo de la narrativa utilizada en los libros de texto obligatorios de la Secretaría de Educación Pública desde 1959.

${ }^{30}$ J. Castañeda y R. Pastor, Limites en la amistad México y Estados Unidos, México, Joaquín Mortiz / Planeta, 1989.

${ }^{31}$ A. Riding, Vecinos distantes. Un retrato de los mexicanos, México, Joaquín Mortiz, 2002.

${ }^{32}$ J. Z. Vázquez y L. Meyer, México frente a Estados Unidos. Un ensayo histórico, 1776-2000, México, FCE, 2001, p. 233.

33 S. Loaeza, "The Changing Face of Mexican Nationalism”, en D. Baer y S. Weintraub, The NAFTA Debate: Grappling with Unconventional Trade Issues, Boulder, Lynne Rienner, 1994.

${ }^{34}$ G. González González et al., The Drug Connection in U.S.-Mexican Relations, San Diego, Center for U.S.-Mexican Studies, University of California, San Diego, 
a Washington de que le preste atención especial como lo apunta el intento fallido de negociar un acuerdo integral migratorio; ${ }^{35}$ y con frecuencia ha sido blanco de desdén y unilateralismo estadounidense. ${ }^{36}$ Consecuentemente, se recurre con regularidad a la utilización de un discurso político que usa en su narrativa hacia Estados Unidos referentes de suspicacia y desconfianza. El caso más reciente es el de la administración de Felipe Calderón y su respuesta a los escándalos de relacionados con el operativo Rápido y Furioso, la renuncia del embajador Carlos Pascual, entre otros. ${ }^{37}$

Esta investigación incluye un grupo de variables que capturan la paradoja de admiración y desconfianza y que constituyen valores mexicanos condicionados histórica y culturalmente. Para capturar la dimensión sobre los valores fundamentales hacia Estados Unidos, se incluyen variables que miden 1) las actitudes de confianza, desconfianza o indiferencia hacia Estados Unidos, 2) los sentimientos de admiración, desprecio o indiferencia hacia Estados Unidos, ${ }^{38}$ y 3) actitudes pro-americanas vs. anti-americanas medidas por preguntas termómetro con respecto a Estados Unidos. ${ }^{39}$ Las expectativas son las siguientes: la percepción de la vecindad como ventaja

1989; y J. Chabat, "Combatting Drugs in Mexico under Calderon: The Inevitable War”, Documentos de Trabajo del CIDE, México, CIDE, 2010, ibid.

${ }^{35}$ R. Fernández de Castro, "La migración sobre la mesa de negociación”, en R. Fernández de Castro, Cambio y continuidad en la política exterior de México, México, Planeta, 2002.

${ }^{36}$ J. Montaño, "México y Estados Unidos: de San Cristobal a Monterrey", ibid.

${ }^{37}$ E. Malkin y R. Archibold, "U.S. Withholds Millions in Mexico Antidrug Aid", The New York Times, 2010; D. Denise, "U.S. Ambassador to Mexico Ousted 'For Doing his Job”, Miami Herald, 2011; R. A. Serrano, "Congress expands Fast and Furious probe to White House", Los Angeles Times, 2011; y J. Seper, "Commander of Drug Cartel Guilty of Shooting ICE Agents in Mexico", The Washington Times, 2013.

${ }^{38}$ Se construyen variables dicótomas para medir los sentimientos de confianza y admiración, por lo que se colapsan las categorías en dos: 1 para confianza y 0 para desconfianza o indiferencia; 1 para admiración y 0 para desprecio o indiferencia.

${ }^{39}$ Se utiliza una escala de 0 al 100, siendo 0 una opinión muy desfavorable, 100 una opinión muy favorable y 50 una opinión ni favorable ni desfavorable. En 2012, Estados Unidos obtiene la opinión más favorable entre el público mexicano, con 71 puntos en promedio. 
para México debe ser mayor entre los individuos que reportan actitudes pro-estadounidenses y sentimientos de admiración y confianza hacia Estados Unidos.

Para medir las actitudes frente a los extranjeros se utilizaron las siguientes variables: 1) un índice agregado que mide las percepciones anti-extranjeras, ${ }^{40}$ 2) dos variables que miden la contribución positiva de los extranjeros a la economía y la generación de ideas innovadoras ${ }^{41}$ y 3 ) una variable que mide las percepciones de apertura cultural, a partir de la pregunta de si es bueno o malo que las ideas y costumbres extranjeras se difundan en México. ${ }^{42}$

La segunda serie de variables independientes en este modelo son las que miden las actitudes ideológicas y las predisposiciones políticas. Estas incluyen: 1) orientación ideológica-representada por la autodeterminación en términos de una escala de izquierda derecha- y orientaciones partidistas; 2) identidad cultural regional de México -si pertenece a América del Norte o a América Latina-e identidad cultural individual -como latinoamericano, norteamericano, centroamericano o ciudadano del mundo-; 3) sentimientos de orgullo nacional; y 4) valoraciones sobre los principios de liberalismo económico -incluyendo percepciones sobre libre comercio, ${ }^{43}$ globalización y apertura a la inversión extranjera- así como valoraciones de los principios de internacionalismo -incluyendo variables

${ }^{40}$ Se construye un índice agregado compuesto por las percepciones que se tienen de los extranjeros en cuanto a su impacto negativo en seguridad social, laboral y cultural de los mexicanos. Se generó un alfa de Cronbach de .674.

${ }^{41}$ Para capturar las actitudes hacia los extranjeros, se preguntan las percepciones sobre si los extranjeros contribuyen a la economía mexicana y si traen ideas innovadoras. En cada caso, la muestra se dividió en dos y se utilizaron escalas distintas para cada pregunta, por lo que fue necesario recodificar, estandarizar y agregar para formar las variables, ahora representativas de la totalidad de la muestra $(N=2400)$.

42 Se incluye la pregunta si es bueno o malo que se propaguen en México ideas y costumbres extranjeras, con valor 1 si es bueno y 0 si es malo o depende.

${ }^{43}$ Se construye un índice agregado a partir de tres preguntas sobre los efectos del libre comercio: si es bueno o malo para "la economía mexicana", para "el campo mexicano" y "el nivel de vida de personas como usted". Se generó un alfa de Cronbach altamente respaldado por los datos de 0.832 . 
que miden el activismo internacional ${ }^{44}$ y la percepción de importancia del papel de México en el ámbito internacional. ${ }^{45}$

Las expectativas son las siguientes: la percepción de la vecindad como ventajosa para México debe ser mayor entre los individuos con orientación derechista que entre los de izquierda; mayor entre los individuos que se identifican con el PAN y el PRI (partidos que han ocupado la presidencia), que entre los que se identifican con el PRD o los que son independientes; mayor entre quienes ubican a México como parte de América del Norte y entre quienes se asocian con un identidad cultural norteamericana, que entre quienes se identifican culturalmente con América Latina, y menor entre quienes reportan estar muy orgullosos de ser mexicanos.

En cuanto a las valoraciones sobre los principios de liberalismo económico se espera una asociación positiva entre la percepción de la vecindad como ventaja para México y las percepciones del libre comercio como benéfico para la economía, el campo y el nivel de vida de los mexicanos, así como con las percepciones sobre la globalización e inversión extranjera como benéficas para el país. La encuesta señala que los mexicanos son entusiastas respecto al libre comercio y la inversión extranjera directa, temas que, como también lo señala la encuesta, son considerados prioritarios en la relación de México con Estados Unidos.

${ }^{44}$ Para medir el internacionalismo activo -definido éste como participación activa en foros multilaterales- se construyó una variable a partir de dos preguntas: “¿qué es mejor para el futuro de México, tener participación activa en asuntos mundiales o mantenerse alejado de los asuntos mundiales?” y “¿cree usted que México deba participar en las fuerzas de paz de la onU o dejar este tipo de actividad a otros países?”. Se codificó 1 para internacionalista activo (aquellos que respondieron estar a favor de la participación activa en asuntos mundiales en ambas preguntas) y 0 para internacionalista pasivo y aislacionista (que incluye tanto a aquellos que respondieron favorablemente sólo una de las dos preguntas como a aquellos que respondieron negativamente las dos preguntas).

${ }^{45}$ Para capturar la dimensión de las percepciones sobre la importancia de México en el ámbito internacional se utilizan dos preguntas para formar una sola variable con valor 1 para "México es importante y será aún más importante a nivel internacional dentro de 10 años" y 0 para "México no es importante y será igual o menos importante dentro de diez años". 
Las valoraciones de los principios de internacionalismo -incluidas variables que miden el activismo internacional y la percepción de importancia del papel de México en el ámbito internacionaly su vinculación con las percepciones costo/beneficio asociadas con la vecindad son de gran interés para esta investigación. Aún no se ha estudiado empíricamente si en la mente de los mexicanos la relación con Estados Unidos constituye un componente que determina su manera de ver y relacionarse con el mundo. Los resultados darían indicios sobre si, en la opinión pública mexicana, la vecindad con Estados Unidos opera como condicionante del papel que debe de desempeñar México en el ámbito internacional.

Hay una tendencia histórica en la literatura académica y en el discurso político de documentar y presentar a México como altamente vulnerable frente a Estados Unidos. Riding lo captura en Vecinos distantes: "cuando se enfrenta a su vecino del norte, la historia le ha enseñado a México que tiene pocas defensas". ${ }^{46}$ Para tener una imagen detallada de los distintos componentes de las actitudes relacionadas con la vulnerabilidad nacional frente a Estados Unidos se introdujeron al análisis variables que miden vulnerabilidades endógenas y exógenas. ${ }^{47}$ Dentro de las primeras se construyen variables a partir de las evaluaciones socio-trópicas sobre 1) el estado general de la economía y 2) evaluaciones sobre el desempeño del Estado mexicano. Para recopilar las evaluaciones sobre el desempeño del Estado mexicano, se construyó un índice agregado utilizando las preguntas en las que se pide a los encuestados evaluarlo en materia de independencia de México frente al mundo, en términos de igualdad social, desarrollo económico y paz y seguridad interna. ${ }^{48}$ Para recopilar las evaluaciones sobre el estado general de la economía nacional se construyó una variable

${ }^{46}$ A. Riding, Vecinos distantes. Un retrato de los mexicanos, México, Joaquín Mortiz, 2002, p. 376.

47 Para un análisis puntual sobre los componentes de la seguridad nacional en México véase L. Herrera-Lasso y G. González González, "Reflections on the Use of the Concept of National Security in Mexico", en B. M. Bagley y S. Aguayo, Mexico: In Search of Security, Coral Gables, University of Miami, 1993.

${ }^{48}$ Se generó un alfa de Cronbach altamente respaldado por los datos de .828 . 
que toma en consideración dos indicadores de evaluación retrospectiva y prospectiva de la economía. ${ }^{49}$

La relación con Estados Unidos ha planteado históricamente retos que se han centrado en mantener la soberanía política y la integridad territorial. Pastor y Castañeda señalan que "México siempre ha tenido que vivir con la realidad, la amenaza y el temor de la intervención de Estados Unidos en sus asuntos internos". ${ }^{50}$ En la actualidad, dada la asimetría de poder entre los dos países y la enorme dependencia de México con respecto a la economía norteamericana, es razonable pensar que se perciba cierto grado de vulnerabilidad nacional frente a Estados Unidos y que ésta, a su vez, tenga incidencia en el cálculo costo-beneficio de las percepciones individuales asociadas con la vecindad. De ser el caso, y siguiendo el marco teórico de sistemas de creencias y valores instrumentales basados en objetivos fundamentales de política exterior, esta variable fungiría como condicionantes de las percepciones mexicanas que se tengan sobre los costos o los beneficios asociados con la vecindad con Estados Unidos.

Para medir el grado de vulnerabilidad nacional relativa se construyó una variable a partir de dos preguntas distintas: "Comparando con hace 10 años, ¿cree usted que las relaciones de su país con Estados Unidos están mejor o peor?” y "En 10 años, ¿cree usted que las relaciones de su país con Estados Unidos serán mejores o peores?”. En 2010, las respuestas indican una división de opinión, ya que mientras el $40 \%$ del público dijo que la relación está mejor que hace diez años, $52 \%$ contesta peor o igual. Hay un mayor nivel de optimismo de frente al futuro, ya que $50 \%$ opina que la relación bilateral será mejor y $41 \%$ peor o igual. ${ }^{51}$

49 “Con respecto al año pasado, ¿considera que la situación económica del país es mejor, igual o peor?” y “¿Cómo cree usted que será su situación económica el año que viene, mejor o peor?”. Se generó un alfa Cronbach moderado de .693.

${ }^{50}$ J. Castañeda y R. Pastor, Limites en la amistad México y Estados Unidos, México, Joaquín Mortiz/Planeta, 1989, p. 105.

51 Como método de imputación para la construcción de esta variable se utilizó la sustitución por la media (se sustituyó el valor ausente por la media de los valores válidos). Al combinar ambas preguntas se generó un alfa de Cronbach moderado de .67 . 
Las expectativas sobre la incidencia que puedan tener percepciones relacionadas con la vulnerabilidad del Estado mexicano frente a Estados Unidos sobre la evaluación que se haga acerca de la vecindad como ventaja para México son mixtas. Por un lado, en un contexto de debilidad interna (tanto institucional como económica) se podría percibir la vecindad más como un problema dada la amenaza y el temor de la intervención de Estados Unidos en los asuntos internos de México; por el otro, se podría percibir como una ventaja dado que ha sido un factor determinante de la ayuda financiera que ha recibido México por parte de Estados Unidos durante las crisis económicas y más recientemente la ayuda que ha recibido en el combate al narcotráfico.

\section{Resultados}

Los resultados del modelo de regresión secuencial se muestran en la tabla 2. El modelo es estadísticamente significativo y las variables teóricamente importantes también son significativas. En todos las instancias se puede rechazar la hipótesis nula, lo que apunta a una relación lineal significativa entre la variable dependiente, vecindad con Estados Unidos como ventaja para México, y el conjunto de variables independientes para cada caso.

Los resultados del modelo 1 (columna 1, tabla 2) indican una asociación lineal y significativa entre las percepciones vecindady los coeficientes de género, ingreso y región, así como participación en redes de comunicación transnacional. Las opiniones sobre la vecindad como ventaja para México son más probables entre los que viven en el norte, ${ }^{52}$ entre los que reciben remesas de parientes que viven en Estados Unidos, entre los hombres (más que las mujeres), entre los que viajan y entre quienes reciben mayor nivel de ingreso.

Un resultado sorprendente del análisis es que los estimados para las variables de género e ingreso se sostienen aún cuando se incorporan variables que miden los valores, predisposiciones y

${ }^{52}$ Los signos asociados con las regiones apuntan precisamente en la dirección esperada, lineal y positiva para norte y lineal y negativa para sur. 
actitudes (columna 2, tabla 2), así como evaluaciones de vulnerabilidad relativa frente a Estados Unidos (columna 3, tabla 2). A pesar de su tamaño, los coeficientes de género e ingreso son significativos. Es decir, cuando se trata de definir el interés nacional en términos de beneficios asociados a la vecindad con Estados Unidos, ser hombre y tener un mayor nivel de ingreso, cuenta. Estos resultados contrastan con los resultados de Page y Bouton ${ }^{53}$ para el caso estadounidense, donde los componentes sociodemográficos dejan de ser estadísticamente significativos cuando se incorporan en los modelos que explican los objetivos básicos de política exterior, las variables que miden actitudes y valores en la opinión pública americana. ${ }^{54}$ Los resultados contrastantes del caso mexicano apuntan hacia la necesidad de un escrutinio mucho más cuidadoso sobre cómo estas dos variables socio-demográficas afectan de manera directa y significativa las percepciones costo-beneficio que se tienen sobre la vecindad.

Por su parte la edad, el nivel de instrucción formal, la residencia urbana y el nivel de exposición a la información nacional e internacional mediante seguimiento de medios no son significativas ni en los modelos parciales ni en los modelos completos. Este hallazgo es importante teniendo en cuenta la fuerte presencia en la literatura de la teoría de la modernización que estipula que los segmentos más modernos de la sociedad por lo general son más receptivos a la apertura de sus países con el exterior. ${ }^{55} \mathrm{Si}$ bien estos sectores pudieran ser más proclives a la apertura, la evidencia empírica para el caso mexicano señala que dichas características no son relevantes para explicar la diferencia de opinión sobre los beneficios o los costos que tiene para México ser vecino de los Estados Unidos.

A pesar de la prevalencia de las variables de género e ingreso, los resultados empíricos en esta estudio indican que los valores

53 Op. cit.

${ }^{54}$ En el caso americano, los componentes socio-económicos y demográficos tienen un impacto directo sobre los valores y actitudes pero indirecto sobre las preferencias especificas relacionadas con el interés nacional.

55 R. Inglehart, Modernization and Postmodernization: Cultural, Economic, and Political Change in 43 Societies, Princeton, Princeton University Press, 1997. 
histórica y culturalmente condicionados -como las actitudes de confianza / desconfianza, admiración/desprecio y valoraciones de simpatías hacia Estados Unidos-y las predisposiciones políticas e ideológicas -como el liberalismo económico, el internacionalismo activo y el nacionalismo- son, por mucho, los determinantes más importantes de las opiniones sobre la vecindad con Estados Unidos. En su conjunto, este grupo de variables explica la varianza de la variable dependiente -vecindad como ventajamejor que el grupo de variables socioeconómicas; el poder explicativo de la regresión se duplica y se registra un incremento de 10 puntos porcentuales en la $R$ cuadrada corregida ${ }^{56}$ (columna 2 , tabla 2). Cabe señalar que los coeficientes estimados para estas variables se sostienen aún cuando se incorporan, en un tercer paso, evaluaciones sobre la vulnerabilidad relativa de México frente a Estados Unidos (columna 3, tabla 2).

Los hallazgos más sólidos y consistentes se encontraron en las variables que miden actitudes de confianza/desconfianza, admiración/desprecio y valoraciones de simpatías medida por la variable termómetro hacia Estados Unidos. ${ }^{57}$ Los resultados de la regresión múltiple (columna 2, tabla 2) indican que aquellos que reportan actitudes de confianza y admiración y que reportan valoraciones de simpatías favorables hacia Estados Unidos son más proclives que el resto a tener valoraciones positivas sobre la vecindad. Los coeficientes de regresión para estas tres variables indican efectos independientes, importantes y estadísticamente significativos. Los resultados también indican que, contrario a lo que supone la ambivalencia, los signos de confianza, admiración

${ }^{56}$ Expresa la proporción de varianza de la variable dependiente que esta explicada ajustándose al número de variables independientes.

${ }^{57}$ Los resultados de la regresión simple indican que aquellos que reportan actitudes de confianza hacia Estados Unidos son más proclives que el resto a tener valoraciones positivas sobre la vecindad, con una diferencia de 30 puntos porcentuales sobre aquellos que reportan desconfianza o indiferencia. Asimismo, aquellos que reportan sentimientos de admiración hacia Estados Unidos son más proclives que el resto a considerar a la vecindad más como una ventaja que como un problema, con una diferencia de 26 puntos porcentuales sobre aquellos que reportan desprecio o indiferencia. 
y afinidad apuntan en la misma dirección cuando se asocian de manera independiente con percepciones positivas sobre la vecindad. Cabe señalar que los sentimientos positivos hacia Estados Unidos han mantenido una tendencia creciente desde 2004. En 2012, Estados Unidos es el país que obtiene la opinión más favorable entre el público mexicano con respecto a 23 países de todo el mundo. Además, una mayoría relativa de la población expresa sentimientos de admiración hacia Estados Unidos, alcanzando el nivel más alto en 2012 con un incremento de 15 puntos porcentuales desde 2004. Pero la transformación más relevante es la relacionada con los sentimientos de confianza: la proporción de la población que reportó confianza hacia Estados Unidos se duplicó desde 2004. Este tipo de transformación es poco usual ya que los valores fundamentales condicionados histórica y culturalmente tienden a ser estables a lo largo del tiempo, y cuando cambian lo hacen gradualmente. ${ }^{58}$ Lo que los datos reflejan es una transformación importante en los sentimientos hacia el vecino del norte que, como lo indica el modelo multivariado, inciden de manera importante y estadísticamente significativa en la forma de ver y valorar la vecindad y sus efectos para México.

El modelo también incorporó variables que miden actitudes ideológicas relacionadas con el liberalismo económico, el internacionalismo activo y el nacionalismo mexicano. Las variables relacionadas con la apertura económica, y en concreto aquellas favorables al libre comercio, son las determinantes más importantes de las valoraciones positivas de la vecindad. El índice incluyó tres preguntas relacionadas a los efectos del comercio para "la economía mexicana", para el "campo mexicano" y para "el nivel de vida de personas como usted”. En promedio, aquellos que obtuvieron la puntuación más alta en el índice agregado sobre los efectos del libre comercio son más proclives a ver la vecindad como una ventaja, que como un problema -con una diferencia de 16 puntos porcentuales-, en

${ }^{58}$ B. I. Page y M. M. Bouton, The Foreign Policy Disconnect: What Americans Want from our Leaders but Don't Get, Chicago, University of Chicago Press, 2006; y R. Inglehart, Modernization and Postmodernization: Cultural, Economic, and Political Change in 43 Societies, Princeton, Princeton University Press, 1997. 
comparación con aquellos que obtuvieron la puntuación más baja. ${ }^{59}$ Los coeficientes estandarizados de la variable que mide las opiniones favorables sobre libre comercio se sostienen en todos los modelos de regresión secuencial, lo que señala su importancia y prevalencia en el proceso de formación de preferencias relacionadas con la vecindad. Si bien el Estado mexicano, desde su fundación, ha oscilado entre ciclos de apertura y proteccionismo económico, lo que el modelo estadístico multivariado señala es que, a casi tres décadas de la adopción de una política económica de apertura como modelo de desarrollo nacional, el libre comercio es percibido por los mexicanos como el eje central del desarrollo del país y funge como el determinante más importantes de las valoraciones positivas de la vecindad.

Otro hallazgo relevante es que aquellos que reportan estar "muy orgullosos de ser mexicanos" son más proclives a tener valoraciones positivas sobre la vecindad con Estados Unidos. Aunque de menor importancia relativa, el coeficiente de regresión de la variable orgullo nacional indica un efecto positivo, independiente y significativo en las opiniones favorables sobre la vecindad con Estados Unidos. Los resultados del modelo multivariado nos permiten cuestionar el sesgo defensivo y proteccionista generalmente asociado al nacionalismo mexicano en la literatura académica y el discurso político. Los hallazgos sugieren que, en la percepción ciudadana, se puede ser nacionalista y, a la vez, apoyar políticas que profundicen lazos de interacción con Estados Unidos sustentados en la percepción de los beneficios para México asociados con la vecindad. ${ }^{60}$

Con respecto a las variables que miden las predisposiciones políticas, los resultados indican que la militancia partidista no es significativa; no existen diferencias importantes en las actitudes de los simpatizantes de los tres partidos más importantes o de los independientes, una vez que se controló estadísticamente por otros

${ }^{59}$ Estos resultados reflejan la información de los coeficientes no estandarizados y son estadísticamente significativos.

${ }^{60}$ Otro hallazgo es que el componente del nacionalismo de rechazo a lo extranjero y de superioridad de lo nacional no tienen un efecto importante en las precepciones individuales sobre la vecindad con Estados Unidos. 
factores. La orientación política de izquierda-derecha tampoco tiene significancia estadística. Con respecto a la identidad regional, las expectativas se cumplen: aquellos que se identifican a sí mismos como "norteamericanos" son más proclives a considerar la vecindad con Estados Unidos como ventajosa para México.

En un tercer paso (columna 3, tabla 2), la regresión incorpora variables que miden las percepciones de vulnerabilidad relativa frente a Estados Unidos, ya sea de origen interno (como percepciones sobre el estado general de la economía o satisfacción con los logros nacionales en materia de independencia, desarrollo económico, igualdad social y seguridad interna) o externo (evaluación sobre el estado de la relación bilateral y prospectivas futuras). Los datos muestran resultados importantes. En primer lugar, las evaluaciones socio-trópicas relacionadas al estado general de la economía nacional no son estadísticamente relevantes para explicar la diferencia de opinión en torno a los beneficios de la vecindad. En segundo lugar, destacan los resultados de las variables de satisfacción sobre los logros nacionales; el coeficiente es positivo, lo que implica que cuanto más satisfecho con los logros del Estado en materia de independencia, desarrollo económico, igualdad social y seguridad interna, mejor la opinión sobre los beneficios de la vecindad para México. En tercer lugar, la evaluación que se hace sobre la relación bilateral presenta una relación positiva y robusta: se puede afirmar que cuanto mejor se evalúe la relación de México con Estados Unidos y mejor se considere que va en la dirección correcta, mejor percepción se tiene de la vecindad como ventajosa para México. En términos comparativos, esta variable es la determinante más importante y estadísticamente relevante para explicar la diferencia de opinión en torno a los beneficios de la vecindad.

Lo que los resultados estadísticos muestran es que a menorvulnerabilidad percibida sobre el Estado mexicano -como lo revelan las percepciones sobre el desempeño nacional y las evaluaciones sobre la relación bilateral-, más beneficiosa se percibe la vecindad. Este hallazgo sugiere que los mexicanos perciben que un Estado nacional fuerte y soberano está mejor capacitado para aprovechar los beneficios asociados con la vecindad. Lo que no deja de sorprender es que las percepciones sobre el estado de la 
economía no tengan una incidencia para explicar la diferencia de opinión, lo que sugiere que la vulnerabilidad percibida por los ciudadanos mexicanos frente a Estados Unidos es de corte políticoinstitucional.

Otro hallazgo importante que arrojan los datos es que al incorporar las variables que miden vulnerabilidad relativa frente a Estados Unidos (columna 3, tabla 2), las variables que miden opiniones sobre la "importancia internacional de México" y el "internacionalismo activo" no sólo cobraron relevancia estadística, sino que además revelan una relación negativa con percepciones sobre la vecindad como ventajosa para México. En promedio, la probabilidad de percibir a la vecindad con Estados Unidos como ventajosa para México es menor para aquellos que favorecen una participación activa de México en el ámbito multilateral. De manera consistente, los resultados indican que, en promedio, la probabilidad de ver la vecindad con Estados Unidos como ventajosa es menor también entre los que consideran que México es un actor importante internacionalmente. Es decir, aquellos que favorecen una actuación de México activa en el ámbito multilateral ${ }^{61}$ son más proclives a ver la vecindad con Estados Unidos más como un problema que como una ventaja para México. Este hallazgo sugiere que los mexicanos que perciben a la vecindad más como problema están inclinados a encontrar la solución a los problemas que afectan los intereses de México en el ámbito internacional mediante una participación más activa y a una mayor inserción en los asuntos globales. Y esto representa un gran reto para México, ya que, como lo documenta González González, México aún no es un actor global con el alcance ni la visibilidad que han alcanzado otros países emergentes de tamaño y capacidades comparables y, además, ha respondido con lentitud y dificultad a la recomposición global y los cambios en el sistema internacional del siglo Xxi. ${ }^{62}$

${ }^{61}$ Cabe recordar que esta variable se construyó a partir de preguntas específicas a la participación internacional de México en foros multilaterales con la intención de aislarla de las percepciones que podrían relacionarla con la participación de México en el marco de su relación bilateral con Estado Unidos.

${ }^{62}$ González González documenta los desfases en el modelo mexicano de inserción internacional, entre ellos: el desfase entre capacidades materiales del país 


\section{Conclusiones}

Los hallazgos de esta investigación contribuyen al debate académico sobre el lugar que deben ocupar las preferencias ciudadanas en la formación de políticas públicas, ya que proporcionan evidencia empírica sobre la existencia de sistemas racionales de opinión individual. El modelo multivariado somete a verificación empírica el argumento que cuestiona la capacidad del mexicano común, el de a pie, para definir preferencias políticas en materia de política exterior. Los hallazgos indican que los mexicanos tienen opiniones fundadas, diferenciadas y racionales que manifiestan patrones de coherencia conceptual.

Consistente con el marco teórico de sistemas y valores instrumentales, los resultados señalan que las evaluaciones costo-beneficio asociadas con la vecindad con Estados Unidos dependen menos de las características socio-económicas y demográficas de los mexicanos, y más de los valores fundamentales asociados con la identidad nacional, actitudes relacionadas con los principios de internacionalismo, liberalismo económico y la percepción de soberanía nacional basadas en consideraciones de vulnerabilidad relativa de México frente a Estados Unidos.

Si bien el modelo estadístico multivariado señala que el libre comercio funge como el determinante más importante de las valoraciones positivas que se hacen sobre la vecindad, los hallazgos también indican una clara división entre quienes, por un lado, perciben a México vulnerable frente a Estados Unidos, perciben a la vecindad más como un problema que como una ventaja y favorecen una fuerte participación de México en el ámbito internacional y, por el

y su presencia internacional; el desfase entre las dimensiones y recursos económicos y el nivel de bienestar social; la brecha entre la apertura hacia el exterior y las estructuras e instrumentos diplomáticos apropiados para avanzar con eficacia los objetivos de política exterior y apuntalar su presencia externa; y la vulnerabilidad que implica para México haber concentrado su red comercial con Estados Unidos, excluyendo casi por completo a los centros de crecimiento mundial en Asia y economías emergentes como el grupo de los BRICs. G. González González, "La identidad internacional de México en el siglo xxi”, Documentos de Trabajo del CIDE, http:/ /www.cide.edu, CIDE, 2012, p. 45. 
otro, quienes perciben a la vecindad como ventajosa para México, y perciben al país como menos vulnerable en términos relativos y capaz de aprovechar los beneficios asociados con la vecindad.

En esta investigación no se encontraron indicios de nacionalismo político defensivo ni del proteccionismo económico característicos del siglo pasado: en la percepción ciudadana, se puede ser nacionalista y a la vez considerar la vecindad con Estados Unidos como ventajosa para México. Asimismo, contario a lo que supone la ambivalencia y la complejidad paradójica de admiración y desconfianza hacia Estados Unidos, los resultados empíricos indican que los signos de confianza, admiración y afinidad apuntan en la misma dirección cuando se trata de valorar la vecindad con Estados Unidos y sus efectos para México.

Las percepciones de vulnerabilidad relativa de México frente a Estados Unidos explican una gran parcela de la variación observada en los datos sobre percepciones costo-beneficio asociadas con la vecindad. El hallazgo más importante es que las evaluaciones sociotrópicas relacionadas con el estado general de la economía no son relevantes para explicar la diferencia de opinión y sí lo son las evaluaciones de corte político institucional. La evidencia empírica muestra que independientemente de la condición de instrucción formal, de residencia urbana o regional, y del nivel de exposición a la información nacional e internacional, los mexicanos perciben que un Estado mexicano fuerte y soberano está mejor capacitado para aprovechar los beneficios asociados a la vecindad con Estados Unidos.

El modelo también pone a prueba el argumento de que aquellos que ven a la vecindad más como un problema son aislacionistas. Los resultados del modelo multivariado sugieren que los mexicanos que tienen valoraciones negativas sobre la vecindad se inclinan a encontrar la solución a los problemas que afectan los intereses de México en el ámbito internacional mediante una participación más activa y una mayor inserción en los asuntos globales. Esto sugiere que el reconocimiento de problemas asociados con Estados Unidos pudieran fungir como catalizador importante y significativo de apoyo hacia una política exterior que tenga una presencia multiregional y que incida directamente en el bienestar económico y social de los mexicanos. 
El análisis empírico aquí realizado indica que el mexicano común tiene preferencias coherentes y diferenciadas, con contenido político real. Los datos señalan que el mexicano es capaz de ponderar las ventajas y desventajas asociadas con la vecindad de México con Estados Unidos y elegir la dirección que México debe seguir en el ámbito internacional. En este sentido, la democracia mexicana se verá fortalecida cuando la opinión pública ocupe un lugar importante en la formulación de políticas públicas, específicamente política exterior.

TABLA 1

Objetivos de política exterior de México

\begin{tabular}{lccccc}
\hline & \multicolumn{5}{c}{ \% de “muy importante” } \\
& 2004 & 2006 & 2008 & $2010^{*}$ & 2012 \\
\hline Combatir narcotráfico y crimen organizado & $83 * *$ & 70 & 81 & 75 & 75 \\
Proteger medio ambiente & - & - & 76 & 74 & 75 \\
Promover la cultura Mexicana & - & - & 73 & 74 & 77 \\
Proteger intereses de mexicanos & 88 & 73 & 76 & 73 & 70 \\
Promover la venta de productos mexicanos & 85 & 76 & 71 & 73 & 73 \\
Atraer turistas & - & - & 62 & 73 & 73 \\
Atraer inversión extranjera & - & 67 & 62 & 71 & 66 \\
Proteger fronteras terrestres y marítimas & - & 68 & 65 & 64 & 63 \\
Combatir terrorismo internacional & 78 & 65 & 61 & 62 & 61 \\
Proteger y promover derechos humanos en & 71 & 53 & - & 60 & 60 \\
otros países & & & & & \\
Promover integración regional & - & - & 52 & 57 & 50 \\
Prevenir proliferación de armas nucleares & 77 & 65 & 56 & 54 & 59 \\
Ayudar a mejorar nivel de vida de países & 66 & 55 & 47 & 43 & 51 \\
menos desarrollados & & & & & \\
Fortalecer a la onu & 60 & 56 & 42 & 43 & 46 \\
Ayudar a llevar la democracia a otros países & 55 & 47 & 37 & 43 & 43 \\
Fortalecer a la oEA & - & - & 31 & 34 & 37 \\
\hline
\end{tabular}

Fuente: CIDE, Mexico and the World 2004 and 2006 Surveys, Mexico, the Americas and the World 2008, 2010, 2012. Surveys; www.mexicoyelmundo.cide.edu

*2010 se utiliza como categoría base.

** Este es un estimado ya que en 2004 se pregunta sobre la importancia de "detener el flujo de drogas ilegales hacia Estados Unidos" como objetivo de política exterior para México. 


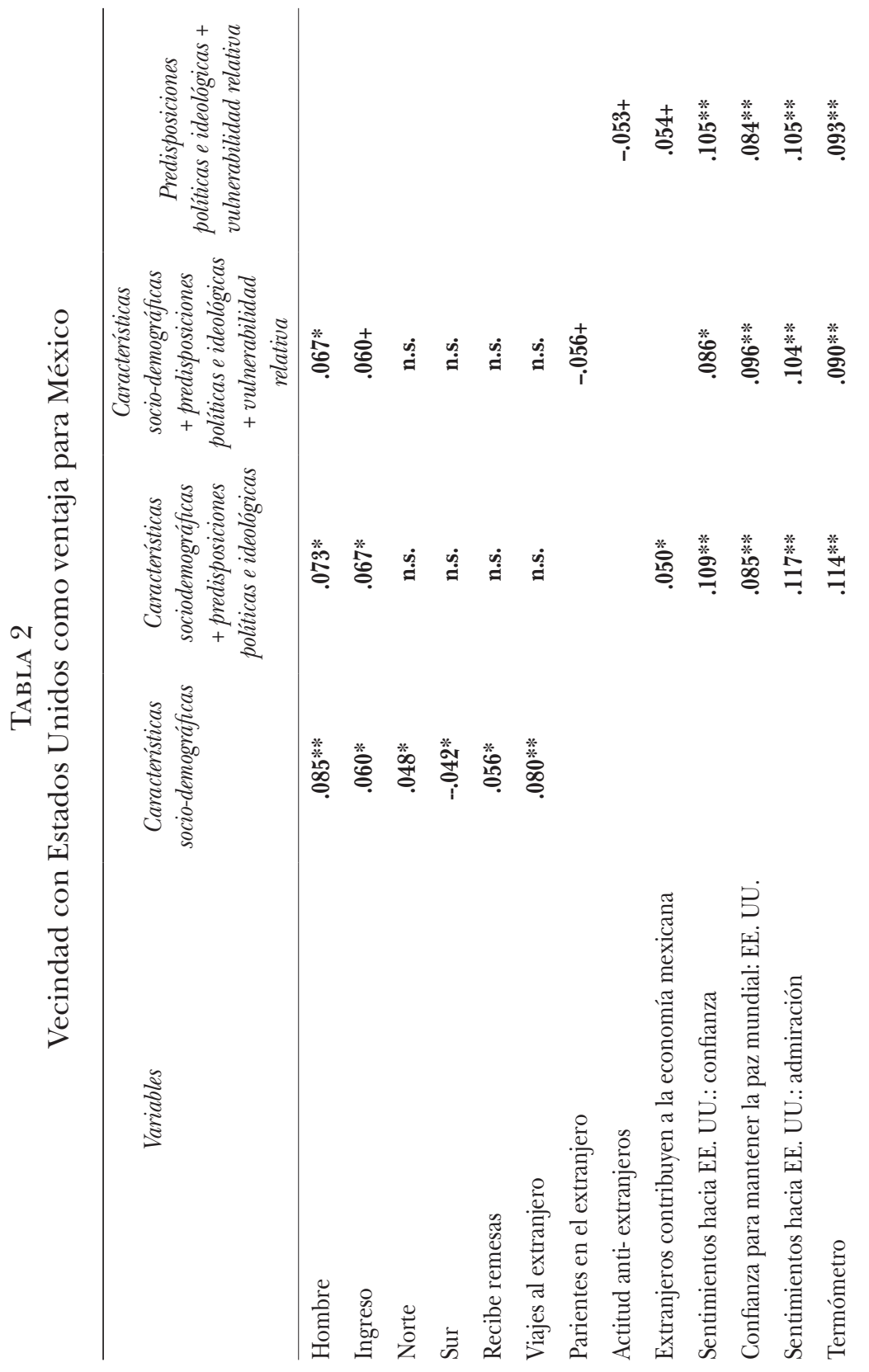




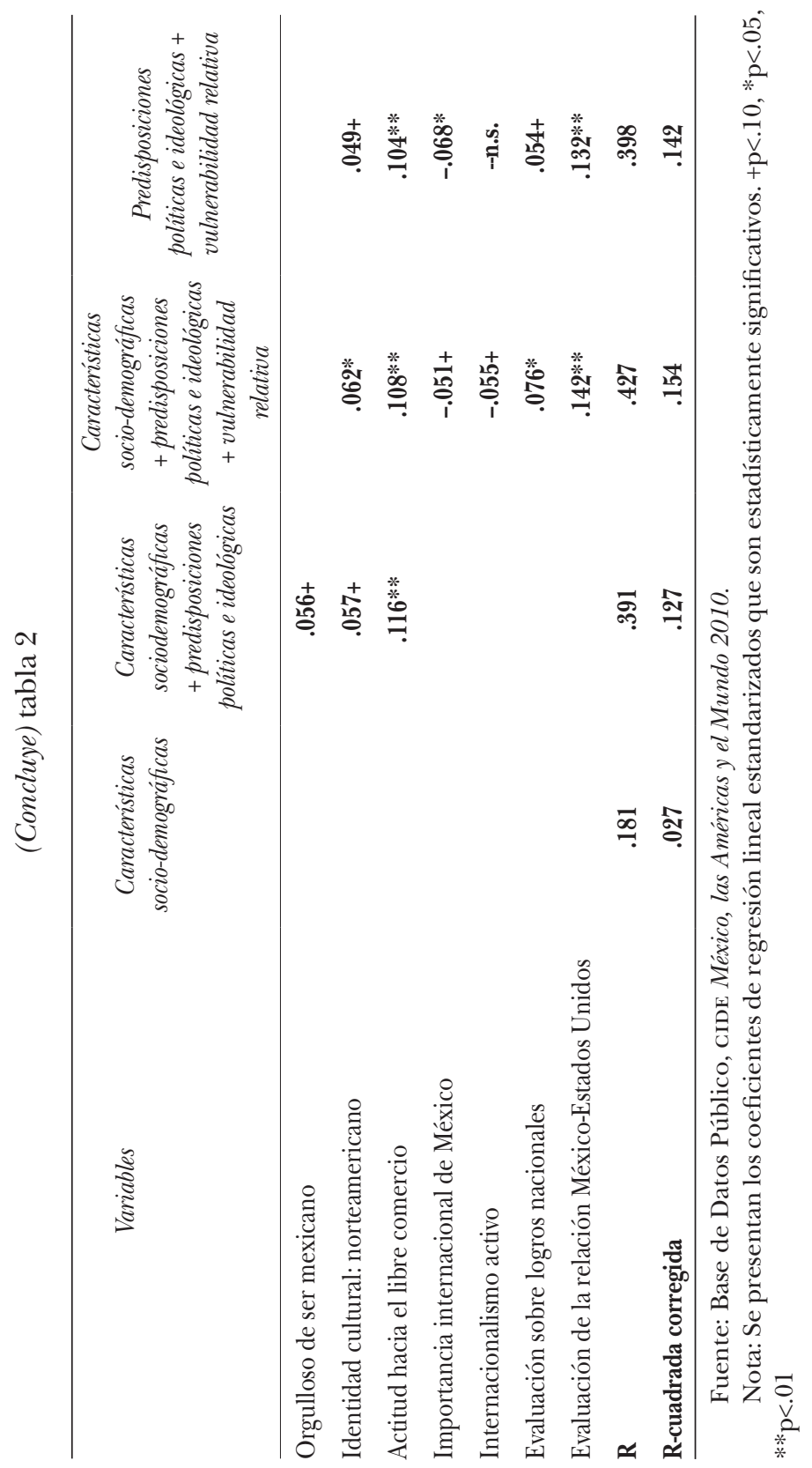




\section{BibliogRAFía}

Almond, G. A., The American People and Foreign Policy, Nueva York, Harcourt Brace, 1950.

—, "Public Opinion and National Security Policy", The Public Opinion Quarterly, 1956, vol. 2, pp. 371-378.

Campbell, A. et al., The American Voter, Nueva York, Wiley, 1960.

Castañeda, J. y R. Pastor, Limites en la amistad México y Estados Unidos, México, Joaquín Mortiz / Planeta, 1989.

Chabat, J., "Combatting Drugs in Mexico under Calderon: The Inevitable War”, Documentos de Trabajo del CIDE, México, CIDE, 2010.

Converse, P. E., "The Nature of Belief Systems in Mass Publics", en D. E. Apter, Ideology and discontent, [Nueva York,] Free Press, 1964, pp. 206-264.

Dahl, R. A., Polyarchy: Participation and Opposition, New Haven / Londres, Yale University Press, 1971.

Davis, C. L., "Mass Support for Regional Economic Integration: The Case of NAFta and the Mexican Public", Mexican Studies/Estudios Mexicanos, vol. 14, núm. 1, 1998, pp. 105-130.

Davis, C. L. y H. A. Bartilow, "Cognitive Images and Support for International Economic Agreements with the United States Among Mexican Citizens", Latin American Politics and Society, vol. 49, núm. 2, 2007, pp. 123-148.

Delli Carpini, M. X. y S. Keeter, What Americans know about politics and why it matters, New Haven, Yale University Press, 1996.

Denise, D., "U.S. Ambassador to Mexico Ousted 'For Doing his Job", Miami Herald, 2011.

Fernández de Castro, R., "La migración sobre la mesa de negociación”, en R. Fernández de Castro, Cambio y continuidad en la política exterior de México, México, Planeta, 2002.

González González, G., "La identidad internacional de México en el siglo xxI", Documentos de Trabajo del CIDE, http:/ / www.cide.edu, CIDE, 2012, p. 45 .

et al., The Drug Connection in U.S.-Mexican relations, San Diego, Center for U.S.-Mexican Studies, University of California, San Diego, 1989.

et al., "Política exterior: opinión pública y líderes", México, Las Américas y el Mundo, 2010, México, cIDE, 2011. 
et al., "Política exterior: opinión pública y líderes", México, las Américas y el Mundo 2012-2013, México, cIDE, 2013.

Herrera-Lasso, L. y G. González González, "Reflections on the Use of the Concept of National Security in Mexico", en B. M. Bagley y S. Aguayo, Mexico: In Search of Security, Coral Gables, University of Miami, 1993.

Holsti, O. R., "Public Opinion and Foreign Policy: Challenges to the Almond-Lippmann Consensus Mershon Series: Research Programs and Debates", International Studies Quarterly, 1992, vol. 36, núm. 4, pp. 439-466.

Inglehart, R., Modernization and Postmodernization: Cultural, Economic, and Political Change in 43 Societies, Princeton, Princeton University Press, 1997.

Kaufman, R. R. y L. Zuckermann, "Attitudes toward Economic Reform in Mexico: The Role of Political Orientations", The American Political Science Review, vol. 92, núm. 2, 1998, pp. 359-375.

Kocher, M. A. y S. Minushkin, "Trade and Investment Policy Preferences and Public Opinion in Mexico", Annual Meeting of the International Studies Association, San Diego, cIDE, 2006.

Krauze, E., "Mirándolos a ellos. Actitudes mexicanas frente a Estados Unidos", Letras Libres, 2007, pp. 32-40.

Lippmann, W., Public Opinion, Nueva York, Harcourt, 1922. , The Phantom Public, Nueva York, Harcourt Brace, 1925.

Loaeza, S., "The Changing Face of Mexican Nationalism", en D. Baer y S. Weintraub, The NAFTA Debate: Grappling with Unconventional Trade Issues, Boulder, Lynne Rienner, 1994.

Malkin, E. y R. Archibold, "U.S. Withholds Millions in Mexico Antidrug Aid”, The New York Times, 2010.

Montaño, J., "México y Estados Unidos: de San Cristóbal a Monterrey”, en R. Fernández de Castro, Cambio y Continuidad en la Política Exterior de México, México, Planeta, 2002.

Moreno, A., "Mexican Public Opinion toward NAFTA and fTAA", en E. J. Chambers y P. H. Smith, NAFTA in the New Millennium, La Jolla y Edmonton, University of California San Diego and University of Alberta Press, 2002.

Morris, S. D., Gringolandia: Mexican Identity and Perceptions of the United States, Lanham, Rowman \& Littlefield, 2005. 
Ojeda, M., Alcances y límites de la política exterior de México, México, El Colegio de México, 2006.

Page, B. I. y M. M. Bouton, The Foreign Policy Disconnect: What Americans Want from our Leaders but Dont Get, Chicago, University of Chicago Press, 2006.

Page, B. I. y R. Y. Shapiro, The Rational Public: Fifty Years of Trends in Americans' Policy Preferences, Chicago, University of Chicago Press, 1992.

Pitkin, H. F., The Concept of Representation, Berkeley, University of California Press, 1967.

Riding, A., Vecinos distantes. Un retrato de los mexicanos, México, Joaquín Mortiz, 2002.

Seper, J., "Commander of Drug Cartel Guilty of Shooting ICE Agents in Mexico”, The Washington Times, 2013.

Serrano, R. A., "Congress Expands Fast and Furious Probe to White House”, Los Angeles Times, 2011.

Stokes, S. C. et al., "Opinión pública y reformas de mercado: Las limitaciones de la interpretación económica del voto”, Desarrollo Económico, vol. 37, núm. 145, 1997, pp. 31-56.

Vázquez, J. Z. y L. Meyer, México frente a Estados Unidos. Un ensayo histórico, 1776-2000, México, FCE, 2001. 